\title{
TOXIC ELEMENTS IN LENTIL, THYME AND JUNIPER IN THE COMPOSITION OF SEMI-SMOKED SAUSAGES USING THE METHOD OF ATOMIC-ABSORPTION SPECTROMETRY WITH ATOMIZATION IN FLAME
}

\author{
Maria Paska
}

Department of Technology of Meat, Meat and Oil and Fat Products

Lviv National University of Veterinary Medicine and Biotechnology named after S. Z. Gzhytsky

50 Pekarska str., Lviv, Ukraine, 79010

maria_pas@ukr.net

\section{Iryna Simonova}

Department of Technology of Meat, Meat and Oil and Fat Products

Lviv National University of Veterinary Medicine and Biotechnology named after S. Z. Gzhytsky

50 Pekarska str., Lviv, Ukraine, 79010

ira.markovuch@gmail.com

Bogdan Galuch

Department of Technology of Meat, Meat and Oil and Fat Products

Lviv National University of Veterinary Medicine and Biotechnology named after S. Z. Gzhytsky

50 Pekarska str., Lviv, Ukraine, 79010

b.halukh@gmail.com

\section{Iryna Basarab}

Department of Technology of Meat, Meat and Oil and Fat Products

Lviv National University of Veterinary Medicine and Biotechnology named after S. Z. Gzhytsky

50 Pekarska str., Lviv, Ukraine, 79010

iryna.basarab@gmail.com

Olga Masliichuk

Department of Technology of Meat, Meat and Oil and Fat Products

Lviv National University of Veterinary Medicine and Biotechnology named after S. Z. Gzhytsky

50 Pekarska str., Lviv, Ukraine, 79010

olia_maruniak@ukr.net

\begin{abstract}
Studies have been conducted into the content of toxic elements in sprouted and unsprouted lentils, juniper fruits and thyme herb, manufactured samples of semi-smoked sausages whose formulation contained the specified ingredients. The samples were prepared for conducting the study. Measuring the mass fraction of heavy metals is based on the selective absorption of electromagnetic radiation of a certain frequency by atoms of substance in a free state. Metal mass fraction in the mineralizate of a sample of food products was calculated by the calibration dependence of absorption magnitude on mass concentration of the metal. Measurement of copper and zinc mass fractions involved an atomization technique in the air-acetylene flame, with a burner heated to a temperature of around $3000{ }^{\circ} \mathrm{C}$; their content was determined by the magnitude of radiation resonance absorption at analytical wavelength corresponding to the examined metal. It was determined that the investigated vegetable raw materials and semi-smoked sausages did not contain toxic elements that exceeded the standard.
\end{abstract}

Keywords: microwave mineralizer, atomic absorption spectrometry, sprouted lentils, unsprouted lentils, juniper fruits, thyme herb, semi-smoked sausages.

DOI: $10.21303 / 2504-5695.2017 .00388$

(C) Maria Paska, Iryna Simonova, Bogdan Galuch, Iryna Basarab, Olga Masliichuk

\section{Introduction}

One of the main sources of contamination of food products is the starting raw materials that do not meet the requirements on the content of chemical elements in them. The elevated content of 
harmful elements in plants and animal organisms can lead to their penetration into the composition of food products [1].

Toxic elements, in particular certain heavy metals, make up a large, and very dangerous in terms of toxicology, group of substances. Elements with paired proton numbers are distributed in nature much better than those unpaired. It was established that the quantitative content of elements in the living matter is inversely proportional to the magnitude of their relative atomic mass. At the same time, increasing a proton number relative to atomic mass and radius of the atom (in groups and subgroups of the periodic system) leads to an increase in the toxicity elements in compounds. The toxicity of metals increases significantly if food contains nitrates [2, 3].

The toxic substances that negatively affect the human organism include cadmium, lead, copper, aluminum, arsenic, mercury [3-6].

In different countries of the world, control over sausages that are sold is executed, for example, in Portugal [7], in the Kingdom of Saudi Arabia [8, 9], in Ukraine [10].

Determining the content of toxic elements in food products is important since it affects the safety of products.

The purpose of present research is to develop a procedure for determining the content of lead, cadmium, copper, zinc, mercury using the method of atomic-absorption spectrometry with atomization in flame and determining the content of toxic elements in lentils, thyme and juniper, and sausage products.

The main task of the study is to prepare the samples of the examined prototypes for undertaking the research using the microwave mineralizer Milestone ETHOS D and to examine toxic elements by means of the atomic-absorbtion spectrophotometer AA240FS Varian and AAS-6300 Shimadzu.

\section{Method of atomic-absorption spectrometry with atomization in flame for determining the content of lead, cadmium, copper, zinc, mercury}

Physical basis of the atomic-absorption method of measurement of heavy metals is the selective absorption of electromagnetic radiation at specified frequency by atoms of substance in a free state. The procedure employs atomization technique in the air-acetylene flame. The magnitude of radiation resonant absorption is registered at the analytical wavelength that matches that of the examined metal. Mass fraction of metal in the mineralized sample is calculated by the granulated dependence of absorbtion magnitude on mass concentration of the metal.

The calculation of mass fraction of the element in the examined sample is carried out automatically.

Formula for the calculation of metal mass fraction (1):

$$
\mathrm{X}=\frac{\mathrm{K} \cdot\left(\mathrm{C}_{\mathrm{a}} \cdot \mathrm{V}_{\mathrm{a}}-\mathrm{C}_{\mathrm{k}} \cdot \mathrm{V}_{\mathrm{k}}\right)}{\mathrm{m}},
$$

where $\mathrm{K}$ is the dilution coefficient; $\mathrm{C}_{\mathrm{a}}$ is the mass concentration of metal in the solution of analytical sample, $\mathrm{mkg} / \mathrm{dm}^{3} ; \mathrm{V}_{\mathrm{a}}$ is the total volume of solution of the analytical sample, $\mathrm{cm}^{3} ; \mathrm{C}_{\mathrm{k}}$ is the mass concentration of metal in the control solution from reagents, $\mathrm{mk} / \mathrm{dm}^{3} ; \mathrm{V}_{\mathrm{k}}$ is the volume of the control solution from reagents, $\mathrm{cm}^{3} ; \mathrm{m}$ is the mass of analytical sample of food products, raw materials, feed, $g$.

Result of measuring the mass fraction of a metal is represented after rounding to two significant digits after the decimal point.

We used for the preparation of samples the microwave mineralizer Milestone DETHOS (Milestone srl, Italy) shown in Fig. 1, 2.

The chosen batch was placed in a weighed empty cup from the microwave mineralizer. We added $6 \mathrm{ml}$ of concentrated nitric acid to each cup as shown in Fig. 3.

Prepared samples were placed in specialized containers and carried over to the microwave mineralizer shown in Fig. 4, 5. 


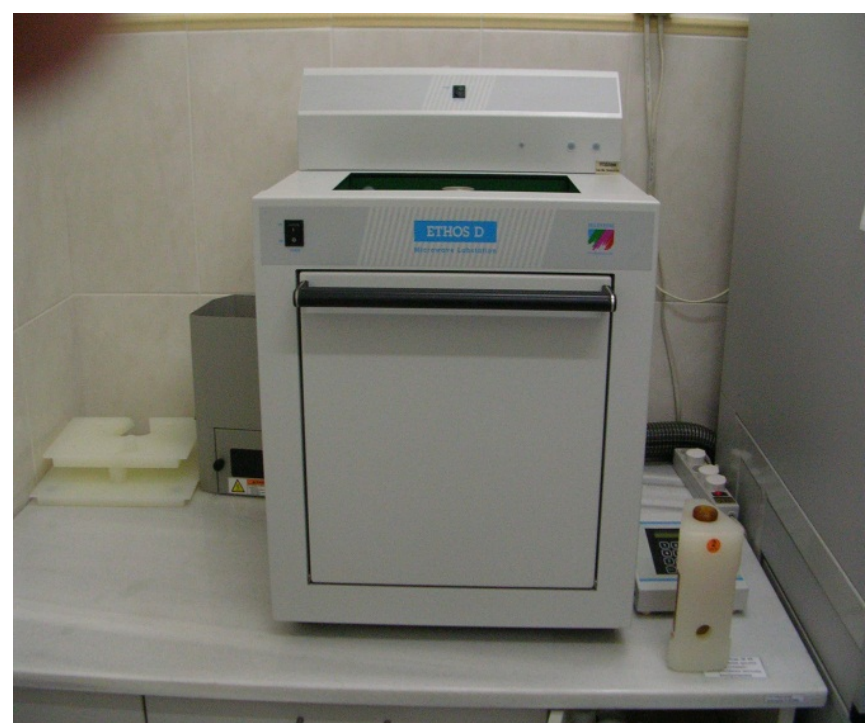

Fig. 1. Mineralizer Milestone ETHOS D

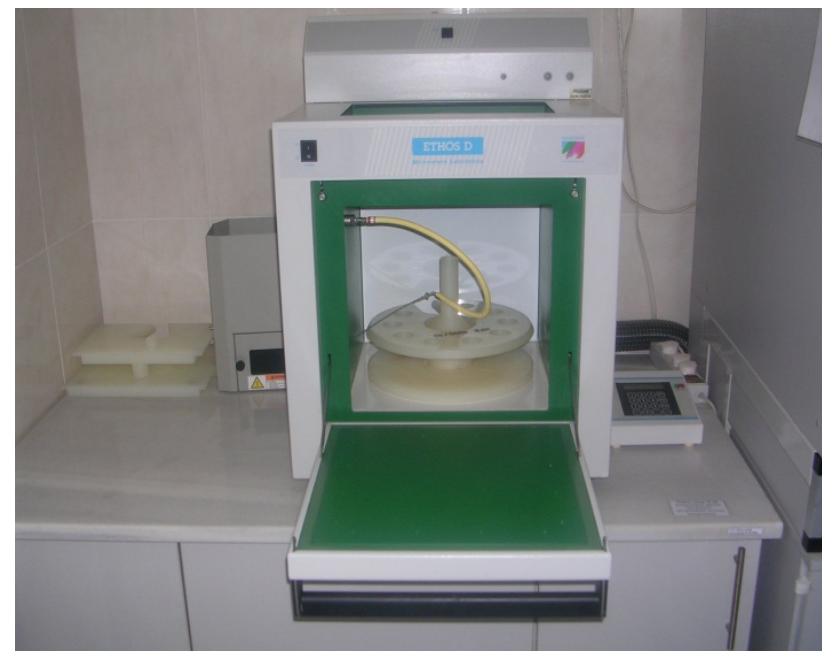

Fig. 2. Mineralizer Milestone ETHOS D

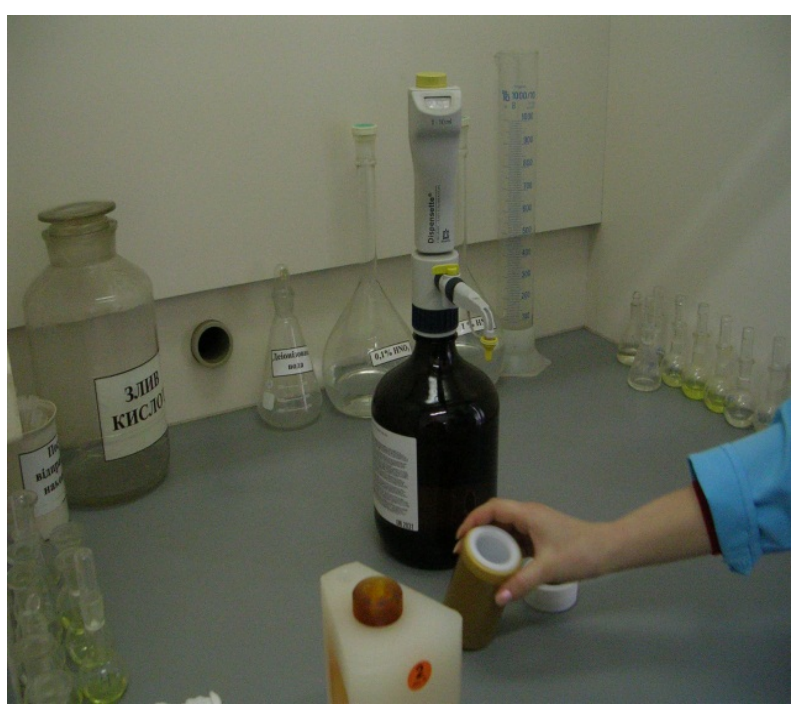

Fig. 3. Adding concentrated nitric acid 


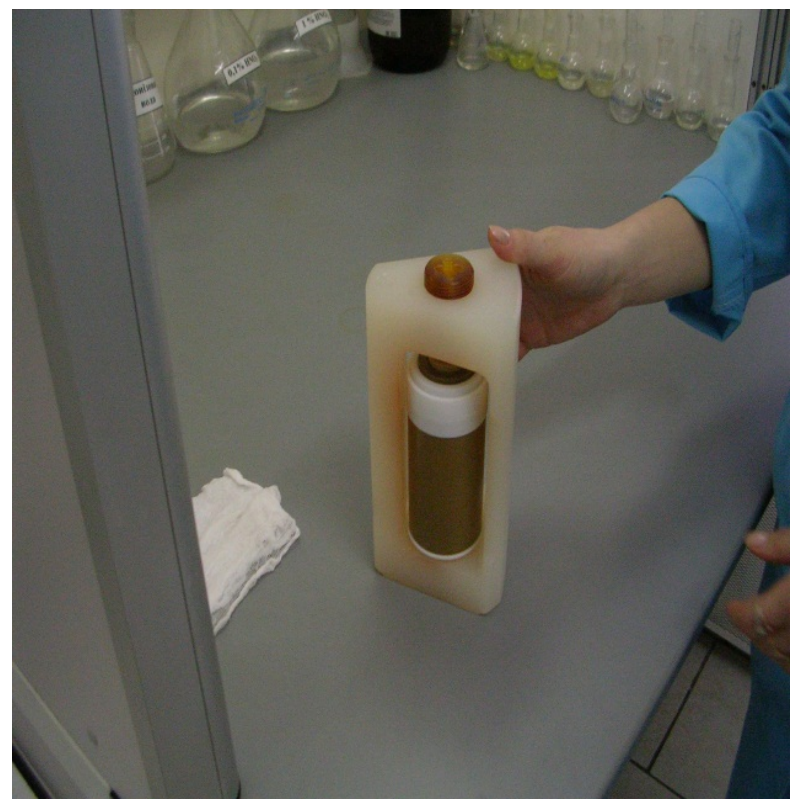

Fig. 4. Container with samples

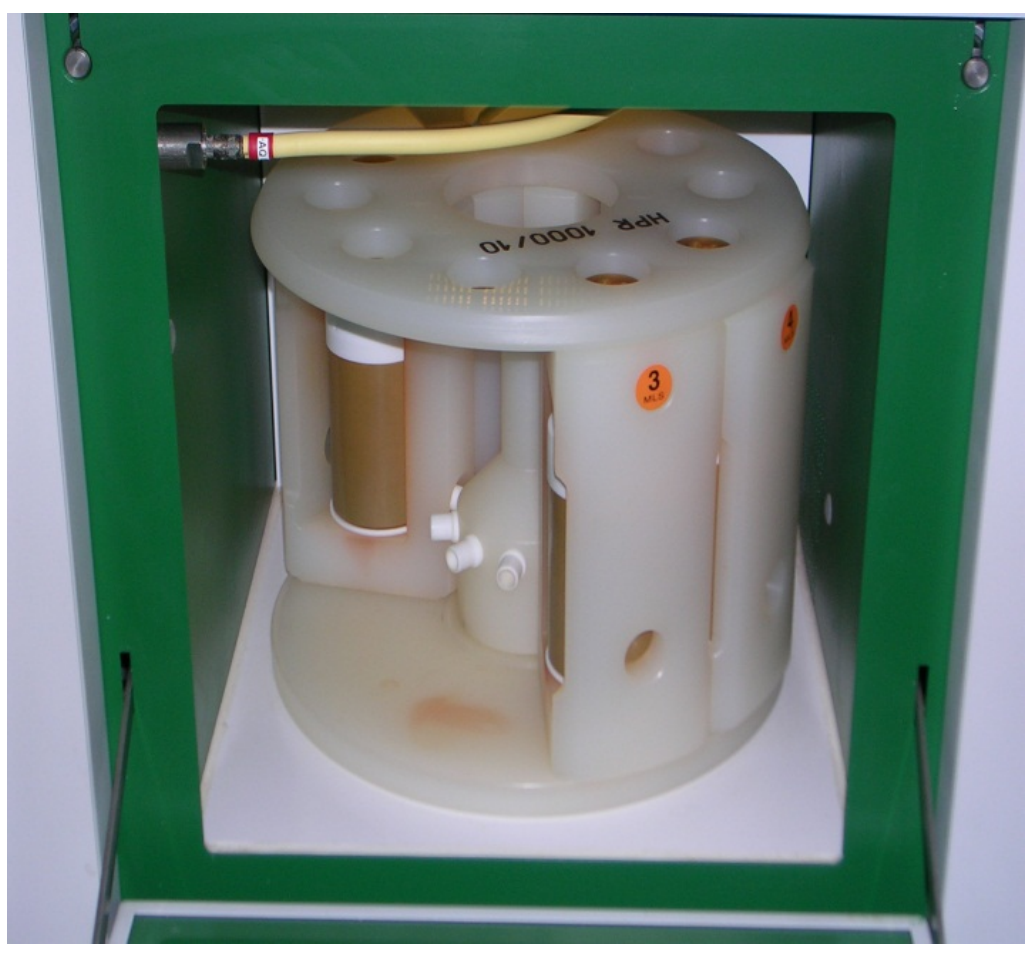

Fig. 5. Placing containers in the mineralizer

We turned on the mineralizer in accordance with the programme of work. Upon completion of operation of the microwave mineralizer, the containers were taken out. The obtained solutions of the samples were poured into measuring flasks of $25 \mathrm{ml}$ with the volume brought to the tag with bidistilled water.

Under the mode established, we measured absorption of the background solution and set the device's readings to zero.

Each solution was measured not less than three times. We accepted result of the measurement as the arithmetic mean of three measurements. 
In order to measure absorption of the solution of analytical sample, we performed control measurement of one of the calibration solutions. Optical absorption was determined of the control solution from reagents and the absorption of analytical samples; after each measurement, the system for the introduction of sample was washed with bidistilled water. Determining a concentration of the examined metal was conducted automatically in line with the calibration chart.

Determining toxic elements of lead and cadmium in sausages was performed using the microwave mineralization, in order to further determine them by the method of atomic-absorption spectrometry with electric thermal atomization.

In the course of research, we employed the atomic absorption spectrophotometer AA240FS Varian (Agilent Technologies, USA) and the atomic absorption spectrophotometer AAS-6300 Shimadzu (Shimadzu, Japan), shown in Fig. 6, 7.

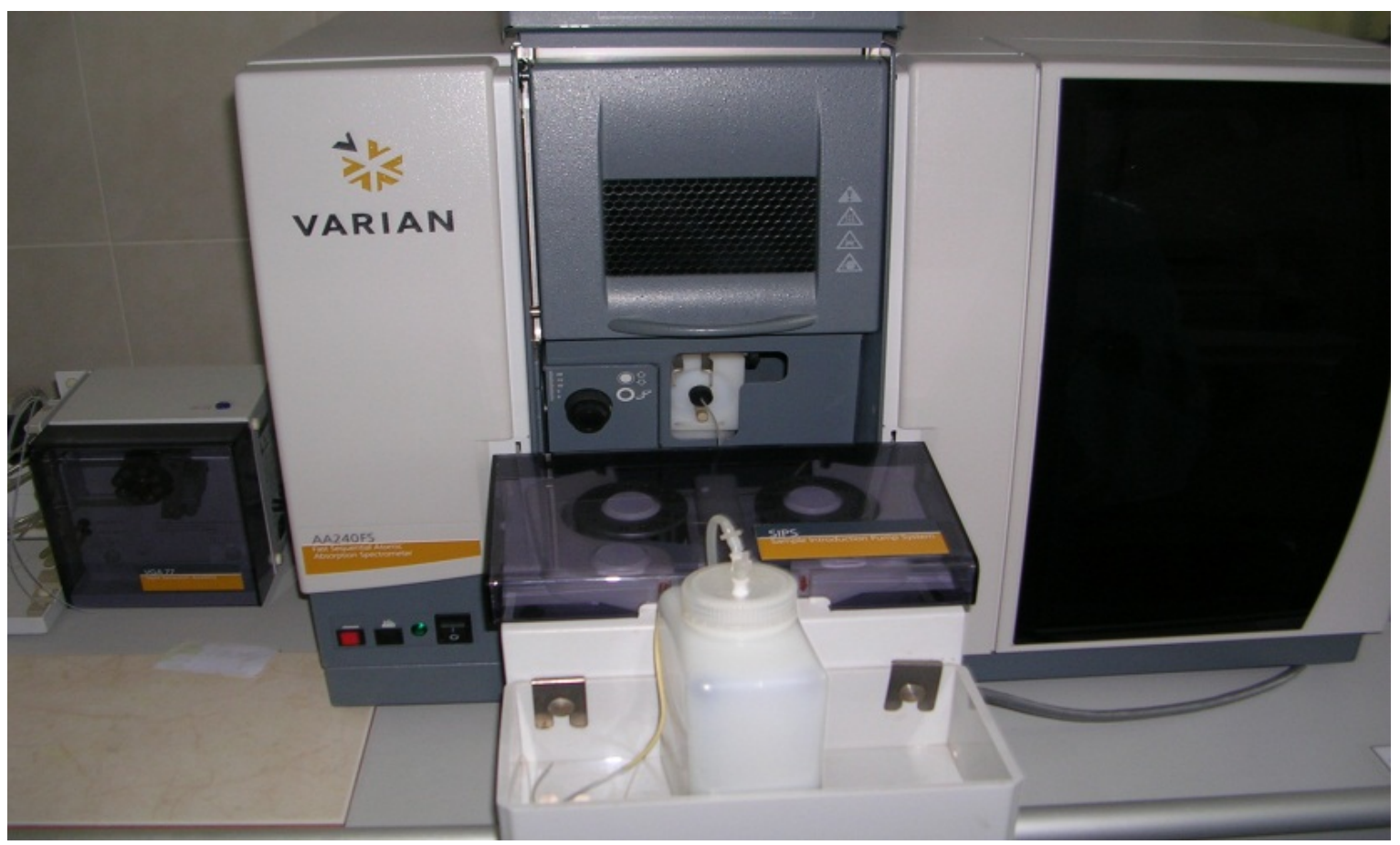

Fig. 6. Atomic absorption spectrophotometer AA240FS Varian

Physical basis of the atomic absorption method for measuring the mass fraction of heavy metals is the selective absorption of electromagnetic radiation at a certain frequency by atoms of substance in a free state. For this purpose, we used a technique of electric thermal atomization, with heating a graphite cuvette to a temperature of about $3000{ }^{\circ} \mathrm{C}$. Mass fraction of metal in the mineralized sample of food products was computed by the calibration dependence of absorption magnitude on mass concentration of the metal. During the research, we weighed the batches in containers form the microwave mineralizer, added $7 \mathrm{~cm}^{3}$ of concentrated nitric acid and $2 \mathrm{~cm}^{3}$ of deionized water, according to the devised procedure [10], to each container, and placed in the mineralizer, which is turned on according to the program, and, upon completion of its operation, we took them out of it. The obtained solutions of the samples were poured into measuring flasks of $25 \mathrm{~cm}^{3}$, with the volume brought up to the tag with deionized water.

When preparing a control solution from reagents, we added $7 \mathrm{~cm}^{3}$ of concentrated nitric acid and $2 \mathrm{~cm}^{3}$ of deionized water into one cup. The samples were next carried over to the device and then investigated.

When measuring a mass share of copper and zinc, we employed atomization technique in the air-acetylene flame, with a burner heated to a temperature of about $3000{ }^{\circ} \mathrm{C}$. The magnitude of radiation resonant absorption was registered at analytical wavelength that matches the examined 
metal. Mass fraction of metal in the mineralized samples was calculated by the calibration dependence of absorption magnitude on mass concentration of the metal. Mineralization of samples was carried out in a muffle furnace.

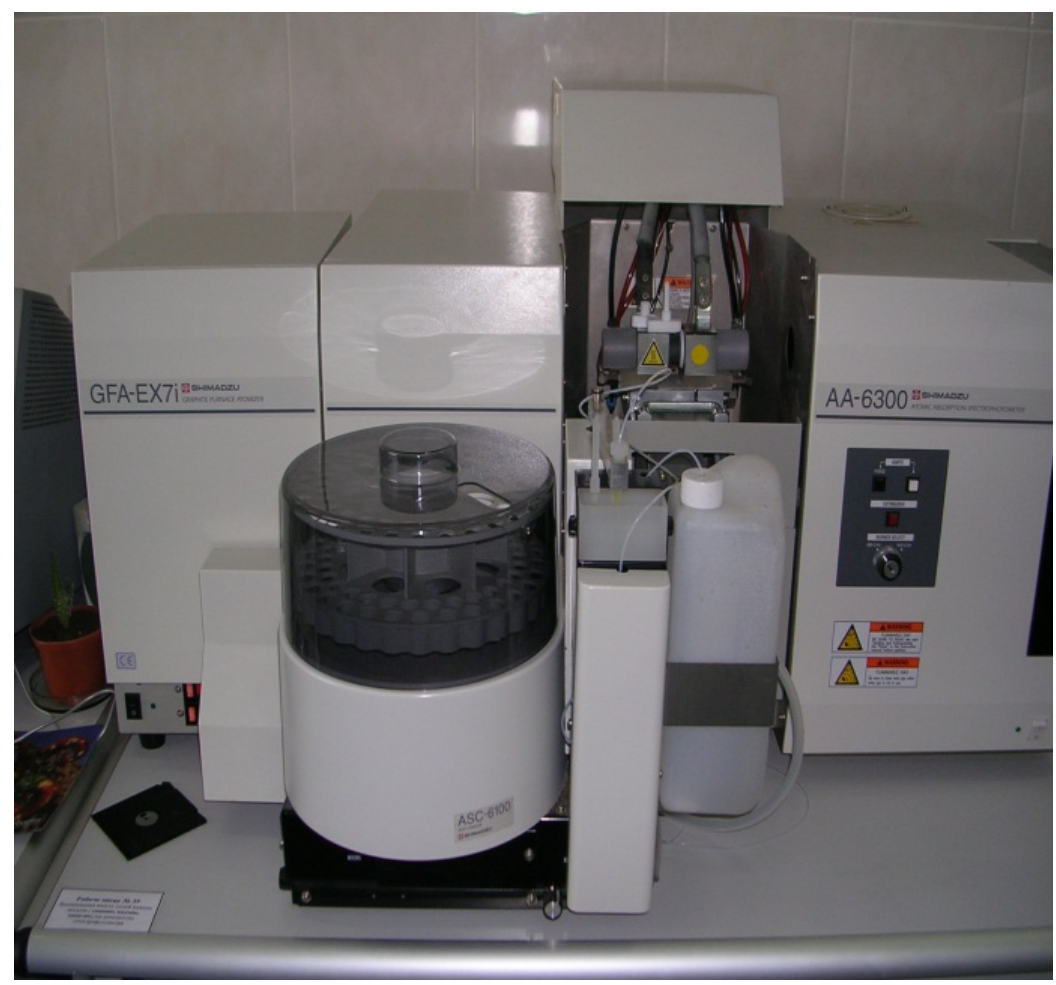

Fig. 7. Atomic absorption spectrophotometer AAS-6300 Shimadzu

\section{Results}

We studied the content of toxic elements in sprouted and unsprouted lentils, juniper fruits and thyme herb, manufactured samples of semi-smoked sausages; the results are given in Table $\mathbf{1 .}$

Table 1

Content of toxic elements and radionuclides in lentils, juniper and thyme, and semi-smoked sausages, $\mathrm{mg} / \mathrm{kg}$

\begin{tabular}{cccccccc}
\hline & Unsprouted lentils & Sprouted lentils & Juniper fruits & Thyme herb & Control & Sample 1 & Sample 2 \\
\hline Lead & 0.09 & 0.15 & 0.09 & 0.23 & 0.06 & 0.05 & 0.05 \\
Cadmium & 0.09 & 0.9 & 0.17 & 0.2 & 0.04 & 0.04 & 0.03 \\
Mercury & 0.01 & 0.01 & 0.002 & 0.001 & 0.005 & 0.005 & 0.005 \\
Arsenic & 0.009 & 0.009 & 0.011 & 0.39 & 0.03 & 0.02 & 0.04
\end{tabular}

Maximally permissible levels of toxic elements, $\mathrm{mg} / \mathrm{kg}$, in lentils are not higher than: cadmium - 0.1, copper -10.0 , zinc -50.0 lead -0.5 , arsenic $-0.2-0.3$, mercury -0.02 ; in the aromatic plants, $\mathrm{mg} / \mathrm{kg}$, not higher than: lead -6.0 , cadmium -1.0 , mercury -0.1 , arsenic -0.5 .

The research results reveal a growth of the content of all elements, except mercury, in the sprouted lentils. The content of cadmium increased from $0.09 \mathrm{mg} / \mathrm{kg}$ to $0.9 \mathrm{mg} / \mathrm{kg}$, which is 8 times larger. The content of lead increased by 0.06 times, arsenic - by 0.003 times. The mercury content 
after germination has not changed. Juniper fruits contain copper in the amount of $6.10 \mathrm{mg} / \mathrm{kg}$, zinc $-11.42 \mathrm{mg} / \mathrm{kg}$. Thyme herb contains copper in the amount of $9.48 \mathrm{mg} / \mathrm{kg}$, which is $3.38 \mathrm{times}$ larger than in juniper fruits. Zinc content is $20.86 \mathrm{mg} / \mathrm{kg}$, which is 9.44 times larger.

The content of lead in thyme herb is 0.14 times greater than that of juniper fruits. There is also an increase in the content of cadmium from $0.17 \mathrm{mg} / \mathrm{kg}$ to $0.2 \mathrm{mg} / \mathrm{kg}$, and a slight increase in the mercury content - by 0.001 times, which does not exceed the maximally permissible levels for the content of toxic elements in the given plants. We received the results of research that indicate the ecological-safe level of raw materials and its safety for At consumers.

At the Department of Technology of Meat, Meat and Oil-fat Products of LNUVM and BT named after S. Z. Gzhytsky we produced samples of semi-smoked sausages using flour from the sprouted and unsprouted lentils, thyme herb, and juniper fruits. We used as a control the semismoked sausage, manufactured without the use of vegetable raw materials. The content of sprouted and unsprouted lentils flour was $10 \%$ by weight of the basic meat raw materials. The content of crushed juniper fruits and thyme herb $-3.5 \%$ by weight of the spices. Produced samples of the semi-smoked sausages were investigated for the content of toxic elements standardized in line with DSTU 4435:2005 "Semi-smoked sausages. General technical specifications". The content of toxic elements in semi-smoked sausages should not exceed, $\mathrm{mg} / \mathrm{kg}$ : lead -0.50 , cadmium -0.05 , mercury -0.03 , copper -5.00 , zinc -70.00 , arsenic -0.10 .

\section{Conclusions}

1. We prepared trial prototypes of the samples of lentil flour, thyme and juniper, samples of semi-smoked sausages for conducting the research using the microwave-mineralizera Milestone ETHOS D.

2. We studied the toxic elements in them by means of the atomic-absorbtion spectrophotometer AA240FS Varian and AAS-6300 Shimadzu. The examined vegetable raw materials and semi-smoked sausages did not reveal the content of toxic elements that would exceed the standard.

The benefits of the given method for examining toxic elements is the application of modern equipment, the speed of research and processing of the results. Disadvantages include expensive maintenance of the equipment.

The results obtained are useful to other scientists, since the study of the content of toxic elements in the flour of lentil, juniper and thyme, using the given method, was conducted for the first time.

\section{Acknowledgment}

Authors of the present article are sincerely grateful to Director of the Lviv Oblast State Laboratory of DerzhProdSpozhivSluzhby in Lviv Oblast, Mr. Roman Petrovich Simonov, for his assistance in conducting the studies.

\section{References}

[1] Bulavkina, T. P., Semenov, S. O. (1999). Perehid vazhkih metaliv z kormiv u produkti zaboyu sviney. Svinarstvo, 54, 129-133.

[2] Pechkurova, E. A., Novikova, O. N. (1997). Opredelenie toksicheskih elementov v produktsii zhivotnovodstva. Zootehniya, 3, 27-28.

[3] Ali Hassan, A., Rylander, C., Brustad, M., Sandanger, T. (2012). Level of selected toxic elements in meat, liver, tallow and bone marrow of young semi-domesticated reindeer (Rangifer tarandus tarandus L.) from Northern Norway. International Journal of Circumpolar Health, 71 (1), 18187. doi: 10.3402/ ijch.v71i0.18187

[4] Skrbic, B., Zivancev, J., Mrmos, N. (2013). Concentrations of arsenic, cadmium and lead in selected foodstuffs from Serbian market basket: Estimated intake by the population from the Serbia. Food and Chemical Toxicology, 58, 440-448. doi: 10.1016/j.fct.2013.05.026 
[5] Delgado-Andrade, C., Navarro, M., Lopez, H., Lopez, M. C. (2003). Determination of total arsenic levels by hydride generation atomic absorption spectrometry in foods from south-east Spain: estimation of daily dietary intake. Food Additives and Contaminants, 20 (10), 923-932. doi: 10.1080/02 652030310001594450

[6] Alves, S. P., Alfaia, C. M., Skrbic, B. D., Zivancev, J. R., Fernandes, M. J., Bessa, R. J. B., Fraqueza, M. J. (2017). Screening chemical hazards of dry fermented sausages from distinct origins: Biogenic amines, polycyclic aromatic hydrocarbons and heavy elements. Journal of Food Composition and Analysis, 59, 124-131. doi: 10.1016/j.jfca.2017.02.020

[7] Alturiqi, A. S., Albedair, L. A. (2012). Evaluation of some heavy metals in certain fish, meat and meat products in Saudi Arabian markets. The Egyptian Journal of Aquatic Research, 38 (1), 45-49. doi: 10.1016/j.ejar.2012.08.003

[8] Nasser, L. A. (2015). Molecular identification of isolated fungi, microbial and heavy metal contamination of canned meat products sold in Riyadh, Saudi Arabia. Saudi Journal of Biological Sciences, 22 (5), 513-520. doi: 10.1016/j.sjbs.2014.08.003

[9] M027-02/10. Vyznachennya vmistu toksychnyx elementiv ta radionuklidiv za vykorystannyam atomno-absorbciynyx spektrofotometriv AA240FS «Varian» та AAC-6300 «Shimadzu» (2010). Lviv: LDRLVM, 51.

[10] DSTU 4435:2005 Kovbasi napivkopcheni (2006). Kyiv: Derzhspozhivstandart Ukrayini, 28. 